\title{
Taming global flood disasters. Lessons learned from Dutch experience
}

\author{
Chris Zevenbergen $\cdot$ Sebastiaan van Herk $\cdot$ Jeroen Rijke $\cdot$ \\ Pavel Kabat • Pieter Bloemen • Richard Ashley • Andrew Speers • \\ Berry Gersonius • William Veerbeek
}

Received: 2 February 2012/ Accepted: 1 October 2012/Published online: 13 October 2012

(C) The Author(s) 2012. This article is published with open access at Springerlink.com

\begin{abstract}
There is a growing international recognition that flood risk management in optima forma should be a programmed and flexible process of continuously improving management practices by active learning about the outcome of earlier and ongoing interventions and drivers of change. In the Netherlands, such a long-term, adaptive flood risk management strategy is now being implemented. This so-called second Delta Programme aims to identify and exploit opportunities and capitalize on short-term benefits and opportunistic synergies that arise from change and will require adaptive policymaking. It also requires the financial and institutional means to operate in a long-lasting way, which at the very least, means engaging stakeholders, gathering and disseminating results and adaptation of future plans. Transferring the Dutch approach to other countries is a major challenge that calls for fundamental changes in institutional arrangements at various levels and thus requires customized programmes for strategic institutional change. Recent examples of transfer will provide important lessons of how institutional change can
\end{abstract}

C. Zevenbergen $\cdot$ S. van Herk · J. Rijke

Department of Civil Engineering and Geosciences, Delft University of Technology, Stevinweg 1, Delft 2628, CN, The Netherlands

C. Zevenbergen $(\bowtie) \cdot$ S. van Herk · J. Rijke $\cdot$ R. Ashley $\cdot$ B. Gersonius · W. Veerbeek

Flood Resilience Group, UNESCO-IHE Institute for Water Education, Westvest 7, Delft 2611, AX, The Netherlands

e-mail: c.zevenbergen@duravermeer.nl

P. Kabat

Environmental Sciences Group, Wageningen University and Research Centre, P.O. Box 47, 6700, AA, Wageningen, The Netherlands

P. Bloemen

PO Box 90653, 2509, LR, The Hague, The Netherlands

R. Ashley

Department of Civil and Structural Engineering, University of Sheffield, Mappin Street, Sheffield S1 3JD, UK 
successfully occur and will contribute insights for other countries that attempting to reform their flood risk management strategies. Continuous monitoring and evaluation and sharing international experiences will become crucial for the effective delivery and wider uptake of these new strategies around the globe.

Keywords Flood disasters - Adaptive delta management - Multi level governance

\section{Introduction}

The frequency and consequences of extreme flood events have increased rapidly worldwide in recent decades (e.g. Bouwer et al. 2007; Kron 2009). The global flood cost has reached a total of USD470bn since 1980 (HSBC 2011). With the occurrence of more than 100 disastrous floods worldwide, 2011 was a record-breaking year (ibid) with extreme floods in Australia (January), Brazil (January), China (June), Colombia (January-June), the United States (June and August), Pakistan (September), Cambodia (September), Vietnam (October), Thailand (November) and in the Philippines (December). Climate change is likely to exacerbate this trend in the near future (e.g. IPCC 2007; Adikrai et al. 2010). The key drivers for these increases are the world's population growth and the increase in socioeconomic activities in flood-prone areas and their growing interdependency on flood protection and drainage infrastructure of which a significant part is of unknown or poor condition (Ashley and Cashman 2006; National Committee on Levee safety 2009; Verwey 2011).

It is timely to take stock of the lessons learned from the past and ongoing flood disasters. In the Netherlands, through investments of more than $€ 1$ bn per year and full-scale in situ experiments, new approaches are now being developed to help to 'live with water' rather than fight it. These are providing the insights, tools and commitment needed to develop and implement long-term robust flood risk management strategies that facilitate adaptive responses to (unforeseen) change through partnership working and active learning (Kabat et al. 2005; Stive et al. 2011; van Herk et al 2011a, b). These strategies are flexible (de Haan et al. 2011) in order to exploit the many opportunities for mainstreaming and integration of flood risk management into national and regional policies, land management practices, urban regeneration and in identifying and delivering multiple benefits at a local level.

\section{Constraints and opportunities}

Historically, floods were viewed as 'acts of God', as disruptions to normality (Mauch 2009). Responses were based on the assumption that floods were external events that affected an unknowing and unprepared society. In the recent past, however, major flood disasters have acted as catalysts for changing flood risk management policies (ibid). The majority of these policies have focused on protection (e.g. Saeijs 1991) and during the 20th century, the scope shifted from indigenous, local-scale to large-scale protection, such as flood embankments and channelization. This shift to large-scale engineering responses was mainly driven by economic development and technological innovation. Nevertheless, the resulting policies remained ad hoc and post hoc responses to disasters, and as a consequence, the measures evolved over time in a piecemeal and fragmented way. This approach has worked reasonably well in the recent past, when the external drivers were assumed to 
change only slowly in comparison with the expected lifetime of the infrastructure systems, but this is no longer tenable due to a faster pace of change (Goodess et al. 2009; Hulme et al. 2009; Gersonius et al. 2010).

More recent experience has revealed important limitations to these engineering-based practices. These include the following: incorrect design assumptions (that is, circumstances for which the systems were designed proved to be more severe than originally predicted), inadequate funding (systems never meeting their design criteria), and poor maintenance (the performance of the systems declining over time) (e.g. Gordon and Little 2009).

Towards the end of the 20th and early in the 21st century, the context of flood management shifted to a risk-based management strategy in which flood risk is defined as the probability (of failure) multiplied by the magnitude (impacts) of adverse affect (e.g. Vrijling et al. 1998). Even with this change in concept, a lack of appreciation of the nonstationarity of drivers and the complex system dynamics particularly under the influence of climate and socio-economic changes meant that conventional flood risk assessments were frequently misunderstood as providing a false sense of "full safety" (Milly et al. 2008). Another limitation has been the lack of socio-economic concepts and methodologies to account for secondary economic consequences, such as long-term disruptions to economic chains (ripple effects, Serre et al. 2011). Lack of understanding of the complex linkages between subsystems and services and the cascading effects of one subsystem upon another, such as for example between water supply, energy production and transportation, is a significant constraint to establishing the full benefit and costs of any proposed flood risk management strategy (ibid).

There are many opportunities for reducing flood vulnerabilities in the face of global change and the importance of integrating social and economic as well as technical approaches has now been widely accepted (e.g. Scheur et al. 2011). Whilst ageing infrastructure and building stock in the developed world pose a risk due to increasing vulnerability, this also provides an opportunity to introduce new technologies in the redevelopment process and to adapt infrastructure and buildings to enhance flood resilience (e.g. van Ree et al. 2011). Urban restoration, regeneration and modernization can be a key driver of economic development, both as a result of the initial investments required and the benefits that will accrue over time (e.g. formerly flood-prone areas may become available for productive use). Conversely, many new economies and developing countries do not have to deal with the legacy of inadequate or declining assets and investments, and this provides an opportunity for them to use the lessons from the developed world to avoid the past mistakes and utilize new innovative technologies, ideas and best practice especially with regard to interconnecting systems (e.g. Li 2011).

\section{The Netherland's delta programme}

The Netherlands is one of the most flood vulnerable countries on the planet with more than $60 \%$ of the land area located in flood-prone areas, hosting 9 million residents and roughly $65 \%$ of the country's gross national product (Kabat et al. 2005). Flood safety is not taken for granted, but a huge and continuous effort is required to protect the country against flooding. Currently, the Netherlands is protected from storm surges and river floods by ongoing reinforcement of the flood protection system comprising coastal dunes, dikes and storm surge barriers: the Delta Works. These were developed and implemented by the first Delta Committee in the 2nd half of the 20th century in response to the major flood disaster of 1953 in the first Delta Programme. The safety standard for the reinforcement of the flood 
defence systems at the time was determined by a combination of the investments required to raise and/or strengthen the flood protection system and the expected reduction in potential direct damage cost (the so-called risk-based benefit-cost design approach) (van Dantzig 1956).

Forty years later, the discussions re-opened again with a fundamental reassessment of the acceptability of flood risk in the Netherlands, for which the increase in economic impacts has to be taken more specifically into account. Simultaneously, scientific evidence has grown revealing that the assumed hydraulic baseline conditions such as storm wave properties and maximum river discharges were most likely to be more severe than originally presumed and climate change and sea level rise would aggravate this (Kabat et al. 2005). Fuelling the debate, two "wake-up" calls came in 1993 and again in 1995 when the river levels of the Meuse and Rhine almost caused dike failure. Following Hurricane Katrina in 2007, the Netherlands reflected on the consequences, much of which were caused by incompetent engineering and a reliance on a single approach of 'complete protection' from flooding (Jonkman et al. 2005). In 2009, the second Delta Committee was established and on November 29th 2011, the Delta Act was unanimously accepted in the Dutch Senate including the allocation of $€ 1$ bn per year in the Delta Fund (Delta Commission 2011). For the first time, the nation has embarked upon a programmed and anticipatory strategy to provide increased safety from flooding. This strategy, developed by the Commission, is based on an integrated vision of how to keep the Netherlands safe, and also at the same time to secure its water resources (Kabat et al. 2005; Stive et al. 2011; Katsman et al. 2011). At the heart of the second Delta Programme is resilience: striving towards an appropriate balance between protection, prevention and preparedness, both now

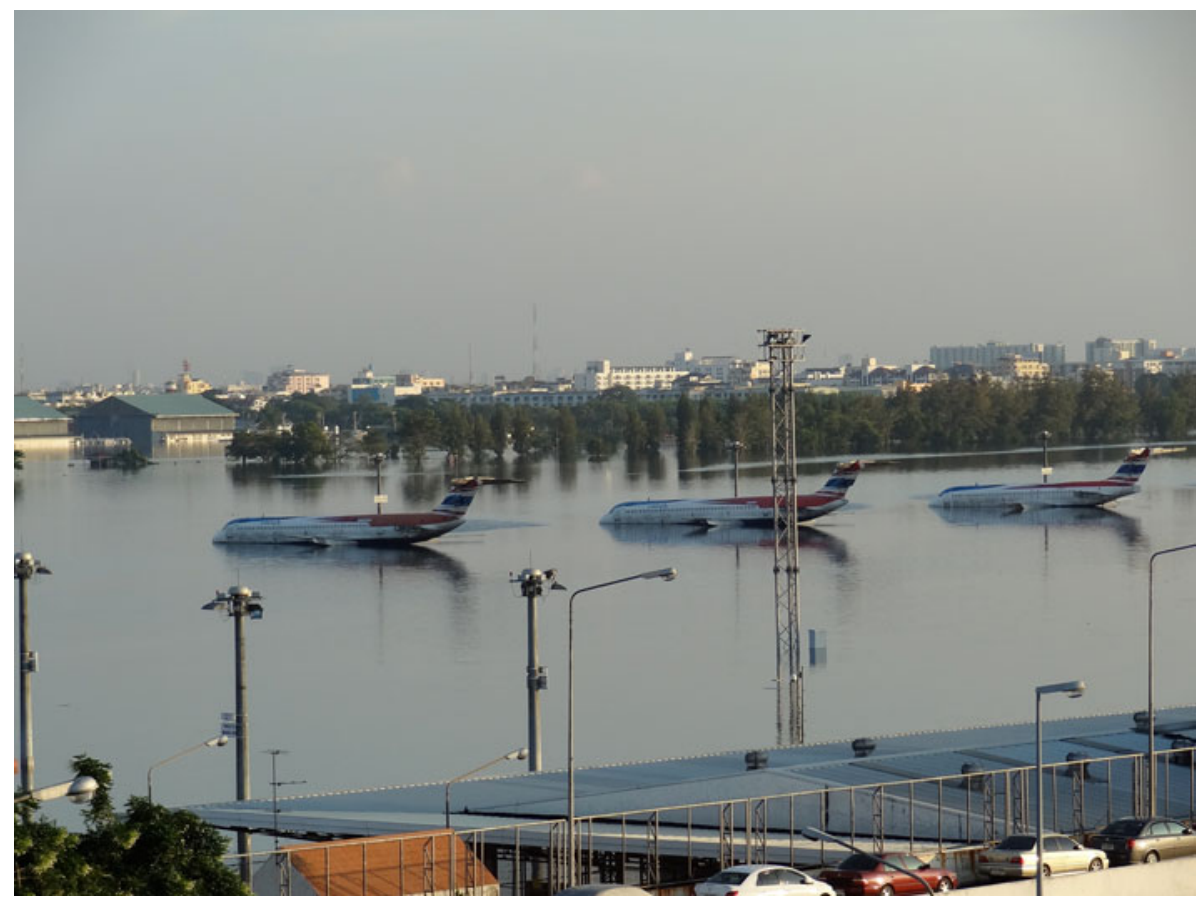

Fig. 1 Recent flooding in Bangkok (photo by Adri Verwey, Deltares) 
and into the future (Gersonius et al. 2010). This is in line with the EU Flood Directive in which flood risk management plans should focus on prevention, protection and preparedness (EC 2007) (Fig. 1).

The Delta Programme has a long-term vision (up to 2100) which provides time to explore and test innovative approaches and technologies and to allow implementation over a long timeframe; thus creating the conditions under which continual improvement and adaptation can be fostered in a learning by doing process. Two of the innovative approaches, which are currently implemented, are Building with Nature (coastal systems) and Room for The River (river systems) (Katsman et al. 2011). Both aim to build in (more) flexibility and/or robustness into the primary flood protection infrastructure in the Netherlands, using both natural processes, and more sustainable land use planning to create room for water to expand during high flows. Another innovation is the Multi-Level Safety (MLS) approach, which holistically addresses the whole 'safety chain' ranging from protection (1st layer: e.g. dikes), to prevention (2nd layer: e.g. spatial planning) and finally to preparedness (3rd layer: e.g. emergency response and recovery plans). Building on previous demonstrations in for example, the city of Dordrecht (van Herk et al. 2011a, b), pilot projects will be delivered within the Delta Programme to explore the potential of MLS to reduce current risk levels further (but in an economically efficient way) by using responses which have previously been outside the scope of flood risk management policies, such as creating more sustainable spatial urban form by accommodating excess flows that exceed the defences (in e.g. blue corridors) and minimizing damage to infrastructure and buildings (2nd layer) (Fig. 2).

A key element of the programme is its so-called adaptive delta management (Delta Committee 2011). This refers to the Committee's ambition to deal with an uncertain future in a rational way by connecting long-term challenges, such as sea level rise (Katsman et al.

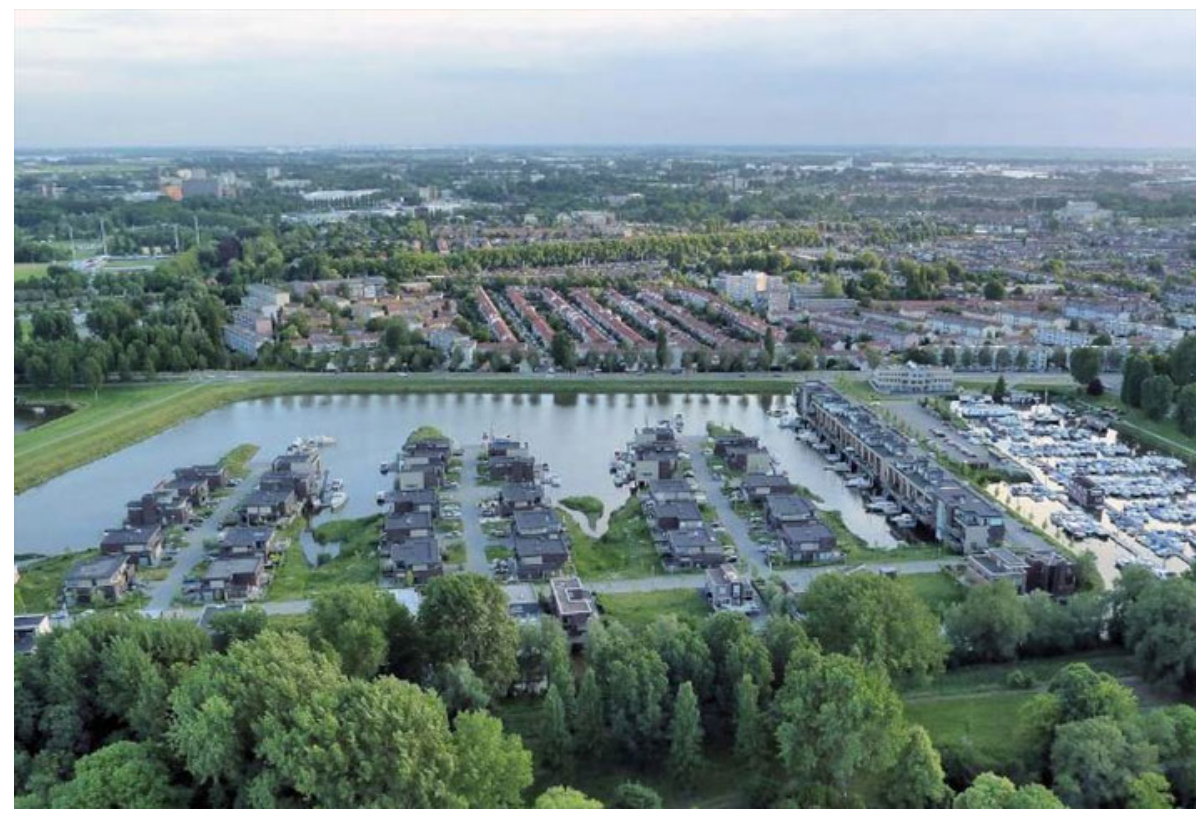

Fig. 2 Full-scale in situ experiment to explore the Multi-Level Safety approach in the City of Dordrecht within the Delta Programme (courtesy City of Dordrecht) 
2011), with short-term outcomes. Adaptive delta management is a cyclical process that utilizes new knowledge to improve longer-term planning and shorter-term adaptation. Thus, longer-term plans are never complete, but are continuously adapted to changing circumstances, including those circumstances brought about by the Delta Programme's own interventions (Kabat et al. 2009). In this way, shorter-term responses that have proven successful should, where possible, be included in subsequent interventions. The approach promotes 'opportunistic adaptation' (incorporation of adaptation into urban renewal, regeneration or development and other shorter-term responses (Veerbeek et al. 2012) and 'mainstreaming adaptation' (uptake of knowledge into longer-term planning and policy processes (Gersonius et al. 2012).

After the installation of the Delta Commissioner in 2010, the Delta programme initiated a planning process in which so-called Delta Decisions are being developed (scheduled for 2014). Coordinated by the Delta Programme, relevant government agencies of the national, regional and local government levels collaborate with community groups and the private sector to determine and understand the challenges of the short and long term, develop potential and consecutively preferential adaptation strategies which lead to the establishment of a set of Delta Decisions that set out a plan for the future. The advantages of such a 'programmed' approach are simultaneously to promote flexibility (including the ability to take immediate advantage of cost savings or benefits) and also to incorporate 'no- or lowregrets' responses into the interventions made. In addition, the approach helps to retain a clear long-term focus that serves to foster a shared political commitment for ongoing investment through demonstration of tangible results and an evidence-based approach to long-term planning. A further factor that has strengthened the political commitment is the potential for the export of Dutch knowledge and technology to the emerging international market for delta technology.

\section{Lessons from the Dutch for other countries}

On October 20, 2005 after hurricane Katrina and the devastating breaching of the levees in New Orleans, former Director of the Dutch Public Water Works, Jan Hoogland, made a statement to the US Congress on flood protection policy that emphasizes the need for continuous learning: "Each flood disaster in the Netherlands-from the 13th century onwards - has brought us new lessons to be learned for keeping our country habitable, livable, and attractive to citizens and businesses."(Hoogland 2005). It is clear that flood risk management is not an end unto itself, but a process of continual improvement and adaptation. Historically, flood events have often prompted 'knee-jerk' responses from politicians and others. Such approaches are unlikely to deliver innovation and effective adaptation (Brown et al. 2011); the most likely outcome is reliance on conventional ('we know it works') solutions that are understood by incumbent regimes, yet it is doubtful that these 'technologically locked-in' responses will provide the best solutions in the face of change (Newman et al. 2011).

After Katrina, the need for absolute protection has urged the construction of a number of large, traditional flood defence schemes in the region. At the same time, New Orleans has also started to explore alternative options for dealing with flood risk in more creative ways. During this process, interactive workshops with local experts and Dutch experts have been organized to support Louisiana's new Coastal Plan and New Orleans's Water Plan (USA). These Building Resilience Workshops (Building Resilience Workshop 2012) and Dutch Dialogues (Dutch Dialogues 2009) have provided a collection of innovative ideas, designs 
and strategies, which enhances flood resilience of the urban region and local communities, but implementation still seems to be remote. Whilst the Dutch approach aims to integrate the collection of alternative adaptation strategies through, for example, the MLS concept, it became apparent during the international workshops that such a comprehensive approach is hampered by a fragmented institutional context and a lack of political will to do things differently from the past.

Two other very recent examples showing international interest in Dutch expertise in this field which have led to knowledge transfer are The Bangladesh Delta Plan and the Mekong Delta Plan. In January 2012, Bangladesh and the Netherlands jointly agreed on the drawing up of a Delta Plan for Bangladesh (Partners for Water 2012). The Bangladesh Delta Plan, which will provide a flexible and integrated water management strategy for the next 50-100 years, will be delivered by both countries in a strategic partnership. Creating this institutional setting in Bangladesh aims to guarantee continued commitment and implementation of the Delta Plan, as well as coordination between stakeholders and investments in infrastructure (Partners for Water 2012). The Dutch support comprises the definition of the plan and the design of its organization. Along similar lines, Vietnam and the Netherlands will jointly develop a Delta Plan for the Mekong Delta, based on the recent experiences of the Dutch Delta Programme (Deltares 2011). The Mekong Delta Plan aims to use adaptive delta management: to work with a long-term vision on multiple objectives, whilst implementing incrementally. Defining a proper organization, however, seems more difficult as the governance culture, institutional setting, and existing policy and regulation are not aligned with this new approach. For example, the management of water resources is based on administrative boundaries rather than physical boundaries (e.g. Deltares 2011). Because there is limited collaboration between the government agencies involved, ineffective measures at the level of the whole delta are the result. The approach of the Dutch Delta Programme provides, therefore, an example of how improved collaboration between all of the actors across the whole delta could lead to a comprehensive approach to adapting.

A comprehensive comparison between examples of knowledge and policy transfer to other countries is beyond the scope of this paper. However, the examples described here demonstrate the growing international interest in the Dutch Delta Programme. They also show that adaptive delta management is not an approach that requires a simple technological change from current practice. It demands a fundamental change in institutional capacity at multiple levels including new knowledge and skills, relationships and policy frameworks (e.g. Rijke et al. 2012). Moreover, contexts and transitioning pathways may vary from country to country and should be taken into account.

Subsequent implementation of strategies of adaptive delta management is still due in all countries likely to be affected by rapid change in to flood risks, for example due to sea level rise, including the Netherlands. Analysing the concept of adaptive delta management in various countries and from different international perspectives may therefore also help to provide useful lessons for the Netherlands.

Future research in policy transfer is recommended. This should analyse and compare the transfer of the policy concept of adaptive delta management; the organization thereof using different governance arrangements such as a Delta Programme, Delta Fund, Delta Commissioner; actual strategies developed; and the actual implementation of strategies and measures. It is necessary to monitor these implementation processes actively, as is underway for the Dutch Room for the River programme (Rijke et al. in press). Continuous monitoring and systematic comparisons will facilitate active learning and are an essential ingredient for the effective delivery of these programmes. 
Acknowledgments The authors wish to acknowledge the support and critical advice of the Room for the River Programme Organization.

Open Access This article is distributed under the terms of the Creative Commons Attribution License which permits any use, distribution, and reproduction in any medium, provided the original author(s) and the source are credited.

\section{References}

Adikrai Y, Osti R, Noro T (2010) Flood-related disaster vulnerability: an impeding crisis of megacities in Asia. J Flood Risk Manag 3:185-191

Ashley RM, Cashman A (2006) The Impacts of change on the long-term future demand for water sector infrastructure (In: Infrastructure to 2030: telecom, land transport, water and electricity, OECD. ISBN: 92-64-02398-4

Bouwer LM, Crompton RP, Faust E, Hoppe P, Pielke RA (2007) Confronting disaster losses. Science 218:753

Brown R, Ashley RM, Farrelly M (2011) Political and professional agency entrapment: an agenda for urban water research. Water Resour Manag 25(15):4037-4050

Building Resilience Workshop (2012) Building resilience workshop III. Available at homepage http:// resilienceworkshop.org/

de Haan J, Kwakkel JH, Walker WE, Thissen WAH (2011) Framing flexibility: theorising and data mining to develop a useful definition of flexibility and related concepts. Futures 43:923-933

Delta Commission (2011) www.deltacommissaris.nl/english/topics

Deltares (2011) Towards a Mekong delta plan. M. Marchand, R. Dam, T. Bucx (eds) Prepared by Deltares in commission of the Delta Coordinator of Directorate General Water in the framework of the Mekong Delta Programme. Available at http://www.partnersvoorwater.nl/wp-content/uploads/2011/09/ToR_ MekongDeltaPlan.pdf

Dutch Dialogues (2009) Dutch Dialogues: New Orleans-Netherlands Common Challenges in Urbanized Deltas. In: Meyer H, Waggonner D, Morris D (eds) 80 pp, ISBN: 9789085067764

EC (2007) Directive 2007/60/EC of the European Parliament and of the Council of 23 October 2007 on the assessment and management of flood risks. Official J Eur Union, L228/27

Gersonius B, Ashley R, Pathirana A, Zevenbergen C (2010) Managing the flooding system's resiliency to climate change. Eng Sustain 163(1):15-22

Gersonius B, Nasruddin F, Ashley R, Jeuken A, Pathirana A, Zevenbergen C (2012) Developing the evidence base for mainstreaming adaptation of storm water systems to climate change, Water Research, http://dx.doi.org/10.1016/j.watres.2012.03.060

Goodess CM, Hall JW, Best M, Betts R, Cabantous L, Jones P, Kilsby CG, Pearman A, Wallace C (2009) Climate scenarios and decision making under uncertainty. Built Environ 33(1):10-30

Gordon P, Little R (2009) Building walls against bad infrastructure policy in New Orleans. Mercatus Policy Series. Policy Primer No. 10

Hoogland JR (2005) "Safety in the Netherlands" Statement to the United States Congress, October 20, 2005

HSBC (2011) Climate investment update. HSBC Global Research, 13 October

Hulme M, Pielke R, Dessai S (2009) Keeping prediction in perspective. (Nature Reports Climate Change Issue 11,29 October)

IPCC (2007) Climate Change 2007 (IPCC, Geneva, 2007) Intergovernmental panel on climate change http://www.ipcc.ch/. Accessed 30 Jan 2012

Jonkman SN, Stive MJF, Vrijling JK (2005) New Orleans is a lesson to the Dutch. J Coast Res 21(6):xi-xii

Kabat P, van Vierssen W, Veraart J, Vellinga Aerts PJ (2005) Climate proofing The Netherlands. Nature 438:283-284

Kabat P, Fresco LO, Stive M, Veerman CR, van Alphen L, Parmet BW, Hazeleger W, Katsman CA (2009) Dutch coasts in transition. Nat Geosci 2:450-452

Katsman CA, Sterl A, Beersma JJ, van den Brink HW, Hazeleger W et al (2011) Exploring high-end scenarios for local sea level rise to develop flood protection strategies for a low-lying delta - the Netherlands as an example. Clim Change. doi:10.1007/s10584-011-0037-5. Accessed 30 Jan 2012

Kron W (2009) Flood insurance: from clients to global financial markets. J Flood Risk Manag 2:68-75

Li S (2011) China's huge investment on water facilities: an effective adaptation to climate change, natural disasters, and food security. Nat. Haz. Published online September

Mauch C (2009) in: Natural disasters, cultural responses. In: Mauch C, Pfister C (eds) (Lexington Books), chap. 1. pp 1-17 
Milly PCD, Betancourt J, Falkenmark M, Hirsch RM, Kundzewicz ZW, Lettenmaier DP, Stouffer RJ (2008) Stationarity is dead: whither water management? Science 319(5863):573-574

National Committee on Levee Safety (2009) Recommendations for a National Levee Safety Program: a Report to Congress from the National Committee on Levee Safety, National Committee on Levee Safety, 15 January (Draft)

Newman R, Ashley RM, Molyneux-Hodgson S, Cashman A (2011) Managing water as a socio-technical system: the shift from 'experts' to 'alliances'. Proc. Of the Institution of Civil Engineers. Engineering Sustainability. 164 (ES1). Paper 1000032. doi:10.1680/ensu.1000032. 95-102

Partners for Water (2012) Towards a Bangladesh Delta Plan. Available at www.bangladeshdeltaplan.org

Rijke J, Brown RR, Zevenbergen C, Ashley RM, Farrelly M, Morison P, van Herk S (2012) Fit-for-purpose governance: a framework to make adaptive governance operational. Environ sci policy 73-84 http://dx.doi.org/10.1016/j.envsci.2012.06.010

Rijke J, van Herk S, Zevenbergen C, Ashley R (in press) Room for the river: delivering integrated river basin management in the Netherlands. Int J River Basin Manag

Saeijs H (1991) Integrated water management: a new concept. From treating of symptoms towards a controlled ecosystem management in the Dutch Delta. Landsc Urban Plan 20(1-3):245-255

Scheur S, Haase D, Meyer V (2011) Exploring multi criteria flood vulnerability by integrating economic, social and ecological dimensions of flood risk and coping capacity: from a starting point view towards an end point view of vulnerability. Nat Hazards 58:731-751

Serre D, Lhomme S, Heilemann K, Hafskjod LS, Tagg A, Walliman N, Diab Y (2011) Assessing vulnerability to floods of the built environment-Integrating urban networks and buildings. Proceedings ICVRAM 2011 and ISUMA 2011, 746-753

Stive MJ, Fresco LO, Kabat P, Parmet BWAH, Veerman C (2011) How the Dutch plan to stay dry over the next century. Civil Eng 164:114-121

van Dantzig D (1956) Economic decisions problems for flood prevention. Econometrica 24:276-287

van Herk S, Zevenbergen C, Ashley RM, Rijke J (2011a) Learning and action alliances for the integration of flood risk management into urban planning: a new framework from empirical evidence from The Netherlands. Environ Sci Policy 14(5):543-554

van Herk S, Zevenbergen C, Rijke J, Ashley R (2011b) Collaborative research to support transition towards integrating flood risk management in urban development. J Flood Risk Manag 4:306-317

van Ree CCDF, Van MA, Heilemann K, Morris MW, Royet P, Zevenbergen C (2011) FloodProbe: technologies for improved safety of the built environment in relation to flood events. Environ Sci Policy 14(7):874-883

Veerbeek W, Ashley R, Zevenbergen C, Rijke J, Gersonius B (2012) Building adaptive capacity for flood proofing in urban areas through synergistic interventions, Proceedings of the 7th International Conference on Water Sensitive Urban Design, 21-23 February 2012, Melbourne Australia

Verwey A (2011) www.thailandblog.nl/overstromingen-2011/adri-verwey-hoop-dat-bangkok-droog-kanblijven/. Accessed 30 Jan 2012

Vrijling JK, Hengel W, van Houben RJ (1998) Acceptable risk as a basis for design. Reliab Eng Syst Saf 59:141-150 